\title{
ISC Revisors del número
}

Els articles publicats al número 19 de la revista Llengua, Societat i Comunicació, titulat Reptes de la comunicació especialitzada, han estat revisats pels següents avaluadors:

Marta Albaladejo

Carme Bach

Francesc Bernat

David Bueno

Ona Domènec

Anna Maria Escofet Roig

Rosa Estopà

Anna Forés-Miravalles

Rosa Gil Juan

Cecilia Kindelán

Xavier Laborda

Laia Lluch Molins

Manuel Murillo Rosado

Neus Nogué

Montserrat Payà Sánchez

Sergio Ramos Pozón

Yanna Stefanu 